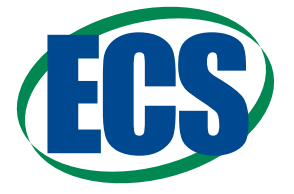

Focus Issue of Selected Papers from IMLB 2016 with Invited Papers Celebrating 25 Years of Lithium lon Batieries

\title{
Influence of Synthesis, Dopants and Cycling Conditions on the Cycling Stability of Doped $\mathrm{LiNi}_{0.5} \mathrm{Mn}_{1.5} \mathrm{O}_{4}$ Spinels
}

\author{
Andres Höweling, ${ }^{\text {a,z }}$ Andreas Stoll, ${ }^{\text {a,b }}$ Dirk O. Schmidt, ${ }^{\mathrm{c}}$ Holger Geßwein, ${ }^{\text {a,b }}$ Ulrich Simon, \\ and Joachim R. Binder ${ }^{\mathrm{a}}$ \\ ${ }^{a}$ Institute for Applied Materials (IAM), Karlsruhe Institute of Technology, 76344 Eggenstein-Leopoldshafen, Germany \\ ${ }^{b}$ Helmholtz Institute Ulm (HIU), 89069 Ulm, Germany \\ ${ }^{c}$ Institute of Inorganic Chemistry (IAC), RWTH Aachen University, 52074 Aachen, Germany
}

\begin{abstract}
The high voltage $\mathrm{LiNi}_{0.5} \mathrm{Mn}_{1.5} \mathrm{O}_{4}$ spinel suffers from severe capacity fade when cycled against a graphitic anode as well as a relatively low theoretical capacity. Using metallic lithium as counter electrode, the stability is improved and the ability of the spinel structure to host $2 \mathrm{Li}$ eq. can be used to improve the capacity. This leads to a theoretical specific energy of $\sim 1000 \mathrm{Wh} \mathrm{kg}^{-1}$. Unfortunately, the cycling of $2 \mathrm{Li}$ eq. involves a phase transition from cubic to tetragonal associated with material degradation. In this work doping is used to improve capacity retention when cycling between 2.0 and $5.0 \mathrm{~V}$. Initial capacities and stabilities are directly dependent on synthesis conditions and doping elements. Therefore, Fe- and Ti-doped spinels are compared with Ru- and Ti-doped spinels and tested at different cycling conditions. The cycling stability can be improved significantly by using reannealed material and by changing the discharge cutoff criteria. Thus a capacity of $190 \mathrm{mAh} \mathrm{g}^{-1}$ is achieved at a rate of $\mathrm{C} / 2$ with a capacity retention of $\sim 92 \%$ after 100 cycles. Furthermore, differences in the discharge behavior between the differently treated Ru- and Ti- doped materials are discussed based on the electrochemical behavior, the particle morphology and in-situ XRD analysis.

(C) The Author(s) 2017. Published by ECS. This is an open access article distributed under the terms of the Creative Commons Attribution Non-Commercial No Derivatives 4.0 License (CC BY-NC-ND, http://creativecommons.org/licenses/by-nc-nd/4.0/), which permits non-commercial reuse, distribution, and reproduction in any medium, provided the original work is not changed in any way and is properly cited. For permission for commercial reuse, please email: oa@electrochem.org. [DOI: 10.1149/2.0521701jes] All rights reserved.

(cc) BY-NC-ND
\end{abstract}

Manuscript submitted September 28, 2016; revised manuscript received December 9, 2016. Published January 7, 2017. This was Paper 494 presented at the Chicago, Illinois, Meeting of the IMLB, June 19-24, 2016. This paper is part of the Focus Issue of Selected Papers from IMLB 2016 with Invited Papers Celebrating 25 Years of Lithium Ion Batteries.

The $\mathrm{LiNi}_{0.5} \mathrm{Mn}_{1.5} \mathrm{O}_{4}$ spinel (LNMO) is a potential candidate for a high-energy cathode material in $\mathrm{Li}$ ion batteries. This is due to the high operating voltage of $\sim 4.7 \mathrm{~V} \mathrm{vs.} \mathrm{Li}^{+} / \mathrm{Li}^{1,2}$ Regardless of the high voltage the spinel offers a lower specific energy compared with other cathode materials (e.g. Li-rich layered oxides with capacities of ca. $\left.220-250 \mathrm{mAh} \mathrm{g}^{-1}\right)$. $^{3-5}$

However, the ability to host an additional lithium on the $16 \mathrm{c}$ octahedral sites $^{6,7}$ when a lithium metal anode is used, leads to an increased specific energy. The theoretical capacity increases up to $294 \mathrm{mAh} \mathrm{g}^{-1}$ and a theoretical energy of around $1000 \mathrm{Wh} \mathrm{kg}^{-1}$ can be reached, which exceeds $900 \mathrm{Wh} \mathrm{kg}^{-1}$, the energy of $\mathrm{Li}_{1.05}\left(\mathrm{Ni}_{1 / 3} \mathrm{Mn}_{1 / 3} \mathrm{Co}_{1 / 3}\right)_{0.95} \mathrm{O}_{2}$ (NMC) materials. ${ }^{8}$ In order to incorporate a second lithium in the spinel structure, the voltage range has to be extended. The lower voltage cutoff is set to $2.0 \mathrm{~V} \mathrm{vs}$. $\mathrm{Li}^{+} / \mathrm{Li}$. The active redox couple in the voltage range below $3.5 \mathrm{~V}$ vs. $\mathrm{Li}^{+} / \mathrm{Li}$ is $\mathrm{Mn}^{4+} / \mathrm{Mn}^{3+}$.

The reduction of $\mathrm{Mn}^{4+} / \mathrm{Mn}^{3+}$ leads to the well-known problem of manganese disproportionation coupled with a possible dissolution of the divalent manganese in the electrolyte. ${ }^{9,10}$ Furthermore the trivalent manganese is Jahn-Teller active and cycling is accompanied by a strong Jahn-Teller-distortion. ${ }^{7,9}$ The c-axis parameter is increased by $\sim 6 \%$ while the a- and b-axis parameters shrink by ca. $0.6 \%$ leading to a phase transition from cubic to tetragonal symmetry. ${ }^{11,12}$ The loss of manganese and the mechanical strain due to the phase transition lead to a severe capacity fade. Therefore, stable cycling of $2 \mathrm{Li}$ eq. in the LNMO $\backslash \backslash \mathrm{Li}$ metal system is not possible.

In order to enhance the electrochemical stability of spinel cathode materials several studies use various elements as dopants (e.g. Cr, Fe, $\left.\mathrm{Ga} ;{ }^{13} \mathrm{Fe}, \mathrm{Cu}, \mathrm{Al}, \mathrm{Mg} ;{ }^{14 \mathrm{C}} \mathrm{r}, \mathrm{Fe}, \mathrm{Co}, \mathrm{Ga} ;{ }^{15} \mathrm{Ti}^{16}\right)$. In many publications the positive influence of $\mathrm{Fe}$ - and/or Ti-doping on the electrochemical stability of LNMO has been shown. ${ }^{13,14,16-20}$ Another promising doping element is Ruthenium. It has also been investigated as dopant in previous studies for the manganese spine ${ }^{21}$ and the LNMO spinel. ${ }^{22-25}$ It leads to an increased rate capability due to a higher electronic conductivity as well as faster lithium diffusion. However, except from

${ }^{\mathrm{z}}$ E-mail: andres.hoeweling@kit.edu the study of Lee and Manthiram, ${ }^{15}$ the given studies only analyze the impact of doping on the cycling of $1 \mathrm{Li}$ eq. Here we use doping to improve the cycling stability in a voltage window of 2.0 to $5.0 \mathrm{~V}$.

Apart from doping as a tool for improving the electrochemical stability, the synthesis conditions and the resulting particle morphology of the powder can have a huge impact on the electrochemical performance.

The usable capacity and rate capability are increased for spinel materials with a distinct octahedral shape of the primary particles. ${ }^{26,27}$ Furthermore the voltage profiles and the capacities are dependent on the synthesis temperature. ${ }^{28-30}$

In this work we show the difference in the electrochemical behavior between Fe-, Ti-doped LNMO and Ru-, Ti-doped LNMO spinels. The influence on cycling stability, capacity and voltage profiles of the different dopants and synthesis conditions are analyzed. Furthermore, the dependence of the cycling stability on the cutoff criteria during discharge is studied in the extended voltage range from $2.0-5.0 \mathrm{~V}$ vs. $\mathrm{Li}^{+} / \mathrm{Li}$.

\section{Experimental}

Synthesis.-A three-step synthesis, based on our previously used two-step syntheses, ${ }^{19}$ was used to produce the iron/titanium and the ruthenium/titanium doped spinel. Generally, the process consists of two spray-drying steps followed by calcination, with an intermediate grinding step.

The used precursor materials are metal acetates of lithium, nickel and manganese $\left(\mathrm{Li}\left(\mathrm{OOCCH}_{3}\right) \cdot 2 \mathrm{H}_{2} \mathrm{O}\right.$, Alfa Aesar; $\mathrm{Ni}\left(\mathrm{OOCCH}_{3}\right)_{2}$ $4 \mathrm{H}_{2} \mathrm{O}$, and $\mathrm{Mn}\left(\mathrm{OOCCH}_{3}\right)_{2} \cdot 4 \mathrm{H}_{2} \mathrm{O}$, Sigma Aldrich) as well as titanium isopropoxide ( $\mathrm{Ti}\left[\mathrm{OCH}\left(\mathrm{CH}_{3}\right)_{2}\right]_{4}$, Merck) and iron nitrate $\left(\mathrm{Fe}\left(\mathrm{NO}_{3}\right)_{3} \cdot 9 \mathrm{H}_{2} \mathrm{O}\right.$, Alfa Aesar) or ruthenium acetate solution $\left(\mathrm{Ru}\left(\mathrm{OOCCH}_{3}\right)_{3}\right.$, Umicore $)$. An aqueous solution of the precursor materials is prepared and used for spray drying (Mobile Minor 2000, Niro A/S). Prior to mixing of the acetates, titanium isopropoxide is dissolved in acetic acid in order to stabilize the solution. The ratio of the precursors is adjusted to a mole ratio of 1:0.5:1.4:0.1:0.03 for 
Li:Ni:Mn:M:Ti (M: Fe or Ru). The produced powder is calcined at $500^{\circ} \mathrm{C}$ for $10 \mathrm{~h}$.

The calcination is followed by a dry grinding step in a planetary ball mill (Pulverisette 5, Fritsch) using yttria-stabilized zirconia beads. The grinded powder is calcined with a heating rate of $5 \mathrm{~K} \mathrm{~min}^{-1}$ to $1000^{\circ} \mathrm{C}$ without a dwell time and cooled to $800^{\circ} \mathrm{C}$ with a dwell time of $10 \mathrm{~h}$. Afterwards the material is cooled to room temperature with a rate of $5 \mathrm{~K} \mathrm{~min}^{-1}$. This intermediate step is necessary as a $\mathrm{RuO}$ impurity phase is formed when this mixed oxide step is not applied. A similar synthesis was also performed by Kiziltas-Yavuz et al. ${ }^{25}$

To obtain well-structured granules of the spinel, a dispersion of the material in water is prepared by grinding in a planetary ball mill for $24 \mathrm{~h}$. The dispersion is then spray dried followed by a final calcination step at $780^{\circ} \mathrm{C}$ for $10 \mathrm{~h}$. The as prepared material is denoted as

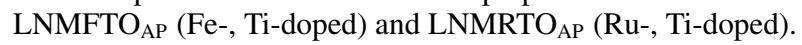

A part of the material is again calcined with the temperature program of the intermediate calcination step $\left(1000^{\circ} \mathrm{C}\right.$ without dwell time followed by $800^{\circ} \mathrm{C}$ for $10 \mathrm{~h}$ ). This repeated temperature step is performed to study the influence of different morphologies on the electrochemical performance. The material is denoted as $\mathrm{LNMFTO}_{\mathrm{HT}}$ and LNMRTO $_{\text {HT. }}$.

Chemical and structural characterization.-The chemical and physical composition of the prepared materials was analyzed by means of various analytical methods. The morphology of the powders is characterized by scanning electron microscopy (SEM) and measurements of the specific surface area $\left(\mathrm{A}_{\mathrm{BET}}\right)$. A field emission scanning electron microscope (Supra 55, Zeiss) was used with an accelerating voltage of $10 \mathrm{kV}$ to obtain micrographs. Nitrogen physical adsorption isotherms were measured with a Gemini VII 2390 (Micromeritics) to obtain $\mathrm{A}_{\mathrm{BET}}$. The calculation was performed according to the BET theory. ${ }^{31}$

The chemical composition was analyzed through inductively coupled emission spectroscopy (ICP-OES). The measurements were performed using an OPTIMA 4300DV spectrometer (Perkin-Elmer). The spectrometer was equipped with Echelle optics and a segmented diode array. Prior to the measurements, the samples were dissolved in nitric acid/hydrochloric acid. All samples were analyzed three times in order to determine the concentrations of $\mathrm{Li}, \mathrm{Ni}, \mathrm{Mn}, \mathrm{Ti}$ and $\mathrm{Fe}$ or $\mathrm{Ru}$.

To resolve the crystal structure powder X-ray diffraction (D5005 diffractometer, Siemens) and Fourier transform infrared spectroscopy (Vertex 70, Bruker) have been applied. Ex situ XRD measurements of the as prepared powder were performed with $\mathrm{Cu} \mathrm{K} \alpha$ radiation and a Sol-X detector. A range of $15^{\circ}$ to $80^{\circ} 2 \theta$ was covered with steps of $0.04^{\circ}$ and a counting time of $12 \mathrm{~s}$. Rietveld refinement was done with the help of TOPAS version 4 from Bruker AXS. For FTIR analysis a minute amount of the sample was pressed in $\mathrm{KBr}$ and spectra were obtained as an average of 15 scans.

In situ X-ray powder diffraction was executed by using a Huber diffractometer with a rotating anode as X-ray generator (Mo-K $\alpha$ radiation). An area detector (Pilatus $300 \mathrm{~K}-\mathrm{W}$ ) enabled the recording of two-dimensional XRD patterns. The 2D diffraction patterns were integrated with the help of the XRDUA software. Measurements were performed with a time resolution of $300 \mathrm{~s}$ using pouch cells fixed at a specially designed sample holder (internal development, KIT). The cells were cycled against lithium foil at a rate of C/10 with an IVIUM CompactStat potentiostat.

Electrochemical impedance spectroscopy (EIS) was applied to evaluate the electronic conductivity. Pellets with a diameter of $12 \mathrm{~mm}$ were pressed with a force of $10 \mathrm{kN}$. Approximately $0.4 \mathrm{~g}$ of the different powders obtained after spray drying prior to heat treatment were used. The pellets were then heat treated according to the different temperature programs. A blocking electrode was created by sputter coating with $\mathrm{Au}$ after heat treatment of the pellets. EIS measurements were performed in a frequency range of $4 \mathrm{MHz}$ to 5 $\mathrm{mHz}$ at an AC voltage of $50 \mathrm{mV}$ with an IM6 spectrometer (Zahner) at a temperature range of 20 to $100^{\circ} \mathrm{C}$.

Additionally, the electronic conductivity was derived from I-V curves measured at single particles. Measurements were carried out in a ZEISS LEO Supra 35 VP SEM. The powder was placed on silicon wafers with a $\mathrm{SiO}_{2}$ layer of $100 \mathrm{~nm}$ thickness. The particles were then contacted with two homemade metalized AFM tips (ATECNC, Nanosensors) via a nanorobotics system (Klocke Nanotechnik). Prior to the measurement the tips were uniformly coated with $\mathrm{Pt} / \mathrm{Ir}$ alloy ( $80 \% \mathrm{Pt}, 20 \% \mathrm{Ir}$ ) by RF sputtering (0.017 mbar Ar/40 W). The obtained coated probes had a tip diameter of approximately 80 to $100 \mathrm{~nm}$.

The electrical characterization was performed with a semiconductor analyzer (Agilent 4156C). The voltage was applied to the right probe while the left probe was grounded and voltage sweeps from $0 \mathrm{~V}$ $\rightarrow 4.5 \mathrm{~V} \rightarrow 0 \mathrm{~V} \rightarrow-4.5 \mathrm{~V} \rightarrow 0 \mathrm{~V}$ were applied under high vacuum conditions $\left(10^{-6} \mathrm{mbar}\right)$. I-V curves were recorded with a current compliance $(\mathrm{CC})$ at $1 \mu \mathrm{A}$. A more detailed description of the measurement setup and procedure can be found in the Supporting Information and in Noyong et al. ${ }^{32}$

Electrochemical characterization.-The spinel powder, carbon black (C-Nergy Super C65, Timcal) and PVDF binder (Solef PVDF $5130 / 1001$, Solvay) were dispersed in N-methyl-2-pyrrolidone (NMP, Merck) with a weight ratio of 85:10:5. Cathode films were prepared by blade coating of the slurry on an aluminum foil current collector followed by drying at $80^{\circ} \mathrm{C}$ for $24 \mathrm{~h}$. For electrochemical measurements two electrode Swagelok-type cells were used. Assembling of the cells was done in an argon-filled glove box $\left(<1 \mathrm{ppm}, \mathrm{H}_{2} \mathrm{O}\right)$. The cells consisted of the prepared cathode film (loading: $5 \pm 1 \mathrm{mg} \mathrm{cm}^{-1}$ ), a glass fiber separator (GF/C, Whatman), $120 \mu \mathrm{l}$ electrolyte consisting of EC:DMC at a ratio of 1:1 and $1 \mathrm{M} \mathrm{LiPF}_{6}$ (LP30, BASF) and lithium foil (Alfa Aesar) as a counter electrode was used.

Galvanostatic cycling tests were performed on a BT2000 battery cycler (Arbin Instruments). If not stated otherwise, a voltage window of 2.0-5.0 V vs. $\mathrm{Li}^{+} / \mathrm{Li}$ was applied. For galvanostatic measurements different C-Rates were used based on the cycling of $1 \mathrm{Li}$ eq.

\section{Results and Discussion}

Morphology and composition.-The SEM micrographs in Figure 1 are used to characterize the morphology of the different doped and thermally treated materials. Due to the spray drying process granules of the primary particles are formed (Figures 1a and 1d). The LNMFTO granules have a size of $17.0 \pm 2.8 \mu \mathrm{m}$ and the granules of LNMRTO have a diameter of $19.6 \pm 7.8 \mu \mathrm{m}$. The morphology and the size of the granules are nearly retained after the heat treatment (see Table I). Both AP materials exhibit polyhedral to octahedral crystal shapes (Figures $1 \mathrm{~b}$ and $1 \mathrm{c}$ ). The size of the primary particles varies between ca. $60 \mathrm{~nm}$ and $700 \mathrm{~nm}$ with a calculated average size of $0.2 \pm 0.1 \mu \mathrm{m}$ for both samples before additional heat treatment. The $\mathrm{d}_{\mathrm{BET}}$ calculated from the specific surface areas is $0.3 \mu \mathrm{m}$ and $0.4 \mu \mathrm{m}$ for $L_{N M R T O}$ AP and $L N M F T O_{A P}$, respectively $\left(d_{B E T}=6 /\left(\rho \cdot A_{B E T}\right)\right.$ $\cdot 10^{-6}$ in $\mathrm{m}, \rho$ is obtained from rietveld refinement). The slightly larger $\mathrm{d}_{\mathrm{BET}}$ values compared to the values derived from SEM micrographs are due to particle aggregation and the thereby reduced surface area.

After heat treatment the size, as well as the crystal shape of the primary particles changed significantly. The calculated $d_{\text {BET }}$ of the materials increased from 0.3 to $0.8 \mu \mathrm{m}$ for $\mathrm{LNMRTO}_{\mathrm{HT}}$ and from 0.4 to $1.7 \mu \mathrm{m}$ for $\mathrm{LNMFTO}_{\mathrm{HT}}$. The particle size is also estimated from the SEM micrographs (see Table I). Based on these values an increase in diameter from 0.2 to $1.0 \mu \mathrm{m}$ for $\mathrm{LNMFTO}_{\mathrm{HT}}$ and 0.2 to $0.7 \mu \mathrm{m}$ LNMRTO $_{\mathrm{HT}}$ is observed, which is in agreement with the $\mathrm{d}_{\mathrm{BET}}$ values.

While the primary particles of all samples exhibit more or less octahedral crystal shapes, the specific crystal morphology varies with dopant and synthesis condition. The starting material displays polyhedral shapes, resulting from octahedral crystals with truncated edges. Thus additional crystal facets are observed. After heat treatment the octahedral shape becomes more distinct. LNMRTO $_{\mathrm{HT}}$ shows very well defined $\{111\}$ facets, while LNMFTO $_{\mathrm{HT}}$ still exhibits $\{110\}$ facets.

Based on the crystal shape and literature results, some predictions about the electrochemical stabilities of the material are possible. Hirayama et al. and Liu et al. found, that the $\{110\}$ facets are vulnerable to manganese dissolution. ${ }^{28,33,34}$ Since the cycling of $2 \mathrm{Li}$ eq. involves 

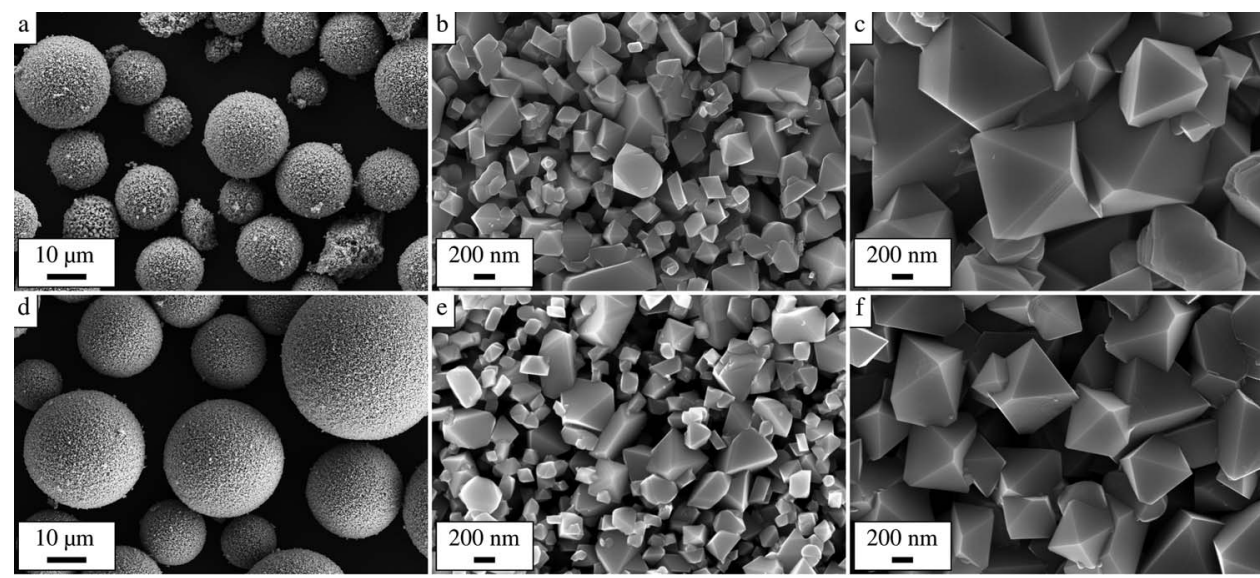

Figure 1. Exemplary SEM micrographs (different magnifications) of the $\mathrm{LNMFTO}_{\mathrm{AP}}$ spinel (a, b) and $\mathrm{LNMRTO}_{\mathrm{AP}}$ spinel (d, e). The micrographs on the right show the particle morphology after additional heat treatment (c: $\mathrm{LNMFTO}_{\mathrm{HT}}$, f: LNMRTO $\mathrm{LT}_{\mathrm{HT}}$ ).

$\mathrm{Mn}^{4+} / \mathrm{Mn}^{3+}$ as the active redox couple below $3.5 \mathrm{~V}$ vs. $\mathrm{Li}^{+} / \mathrm{Li}$, there is a higher risk of manganese disproportionation and dissolution during cycling. This risk of manganese dissolution is enhanced for the truncated particles. Furthermore, the cycling stability and rate capability decrease when the octahedral spinel particles are truncated. ${ }^{26}$

The results of the chemical analysis are listed in Table S1. The expected formula of $\mathrm{Li}_{1.0} \mathrm{Ni}_{0.5} \mathrm{Mn}_{1.4} \mathrm{M}_{0.1} \mathrm{Ti}_{0.027} \mathrm{O}_{4}(\mathrm{M}=\mathrm{Fe}$ or $\mathrm{Ru})$ can be achieved for both different doped materials. After additional heat treatment the chemical composition has not changed.

XRD and FTIR spectrometry are performed to identify the structural differences between the four analyzed materials (s. Figure 2). The XRD patterns are similar for the different treated samples containing the same dopants. However, there are some obvious differences between the LNMRTO and the LNMFTO samples. For the LNMFTO material, the 220 diffraction peak has a slightly higher intensity and is more distinct compared to the LNMRTO material. This suggests a higher occupation of the 8 a tetrahedral site with transition metal ions. ${ }^{13,35,36}$ In the case of LNMFTO it is most likely that either $\mathrm{Mn}^{3+}$ or $\mathrm{Fe}^{3+}$ change position from the $16 \mathrm{~d}$ to the 8 a site, since $\mathrm{Ni}^{2+}$ ions tend to occupy the octahedral $16 \mathrm{~d}$ site. ${ }^{36}$ Furthermore a clear asymmetry of the diffraction peaks, especially the 400 peak, is visible. This peak asymmetry is similar to our previous results on Fe-, Ti-doped spinels. ${ }^{37}$
Phase fractions and lattice parameters are resolved by Rietveld refinement (s. Table II and Figure S2). For the refinement a spinel phase with the $\mathrm{Fd} \overline{3} \mathrm{~m}$ space group and a rock salt impurity phase are used. For the LNMFTO samples large residuals are observed due to the peak shape asymmetry. This asymmetry can be explained by a second spinel phase with considerably larger lattice parameters. As was suggested previously, a second spinel phase with a slightly different composition can exist. ${ }^{37}$ Ruthenium oxide, which is a possible impurity phase for the LNMRTO samples, is not detected with XRD. Thus, the incorporation of ruthenium into the spinel structure can be achieved by the intermediate grinding step and the following calcination.

For all samples larger lattice parameters $\left(\mathrm{LNMFTO}_{\mathrm{AP}}\right.$ : 8.1808(1) $\AA$ and LNMRTO $_{\mathrm{AP}}: 8.1866(1) \AA$ ) compared with undoped LNMO spinels $\left(8.177 \AA^{38}\right)$ and Ti-doped spinels $\left(\sim 8.174 \AA^{16,39}\right)$ are found. Iron is likely to be in high-spin state ${ }^{35}$ and ruthenium in $\mathrm{LiMn}_{2} \mathrm{O}_{4}$ was found to be of tetravalent charge. ${ }^{21}$ The ionic radii of the dopants ( $\mathrm{Fe}^{3+} \mathrm{HS}: 65 \mathrm{pm}$ and $\mathrm{Ru}^{4+}: 62 \mathrm{pm}^{40}$ ) are larger compared with the substituted $\left(\mathrm{Mn}^{4+}: 53 \mathrm{pm}^{40}\right)$ and thus the larger lattice parameters can be explained.

After heat treatment an increase of the lattice parameters to 8.1879(1) $\AA\left(\mathrm{LNMFTO}_{\mathrm{HT}}\right)$ and 8.1903(1) $\AA\left(\mathrm{LNMRTO}_{\mathrm{HT}}\right)$ is observed. This could possibly be due to a slight oxygen loss, which

Table I. Physical properties of the samples.

\begin{tabular}{llllll} 
Sample & $\mathrm{A}_{\mathrm{BET}}\left[\mathrm{m}^{2} \mathrm{~g}^{-1}\right]$ & $\mathrm{d}_{\mathrm{BET}}[\mu \mathrm{m}]$ & $\mathrm{d}_{\text {SEM,P }}[\mu \mathrm{m}]^{\mathrm{a}}$ & $\mathrm{d}_{\text {SEM,G }}[\mu \mathrm{m}]^{\mathrm{b}}$ & $17.0 \pm 2.8$ \\
\hline LNMFTO $_{\mathrm{AP}}$ & 3.3 & 0.4 & $0.2 \pm 0.1$ & $15.8 \pm 3.2$ & $2.44 \pm 0.03$ \\
LNMFTO $_{\mathrm{HT}}$ & 0.8 & 1.7 & $1.0 \pm 0.5$ & $19.6 \pm 7.8$ & $2.95 \pm 0.03$ \\
LNMRTO $_{\mathrm{AP}}$ & 4.5 & 0.3 & $0.2 \pm 0.1$ & $19.2 \pm 6.2$ & $2.31 \pm 0.20$ \\
LNMRTO $_{\mathrm{HT}}$ & 1.7 & 0.8 & $0.7 \pm 0.2$ & $2.80 \pm 0.02$
\end{tabular}

${ }^{a}$ Median diameter of primary particles measured on SEM micrographs $(\mathrm{N}=50)$.

${ }^{\mathrm{b}}$ Median diameter of granules measured on SEM micrographs $(\mathrm{N}=60)$.

Table II. Results of the rietveld refinement of the as-prepared powder samples.

\begin{tabular}{lllllll} 
Sample & $\mathrm{LNMO}_{1}[\mathrm{wt}-\%]$ & $\mathrm{a}_{1}[\AA]$ & $\mathrm{M}_{\mathrm{tet}}[\mathrm{mol}]^{\mathrm{a}}$ & $\mathrm{LNMO}_{2}[\mathrm{wt}-\%]$ & $\mathrm{a}_{2}[\AA]$ & $\mathrm{L}_{1-\mathrm{x}} \mathrm{N}_{\mathrm{x}} \mathrm{O}[\mathrm{wt}-\%]$ \\
\hline LNMFTO $_{\mathrm{AP}}$ & $84.7 \pm 0.3$ & $8.1808(1)$ & $0.040 \pm 0.002$ & $12.8 \pm 0.1$ & $8.223(1)$ & $2.6 \pm 0.4$ \\
LNMFTO $_{\mathrm{HT}}$ & $81.2 \pm 0.5$ & $8.1879(1)$ & $0.047 \pm 0.004$ & $14.2 \pm 0.1$ & $8.227(2)$ & $4.6 \pm 0.6$ \\
LNMRTO $_{\mathrm{AP}}$ & $97.8 \pm 0.3$ & $8.1866(1)$ & $0.026 \pm 0.003$ & - & - & 5.3 \\
LNMRTO $_{\mathrm{HT}}$ & $97.1 \pm 0.4$ & $8.1903(1)$ & $0.034 \pm 0.004$ & - & - & $2.2 \pm 0.3$ \\
\end{tabular}

Indices indicate the two different spinel phases. All spinels crystallize in the $\mathrm{Fd} \overline{3} \mathrm{~m}$ space group.

${ }^{a}$ transition metal ion on 8 a tetrahedral site $\left(\mathrm{M}: \mathrm{Mn}^{3+}\right.$ or $\left.\mathrm{Fe}^{3+}\right)$. 

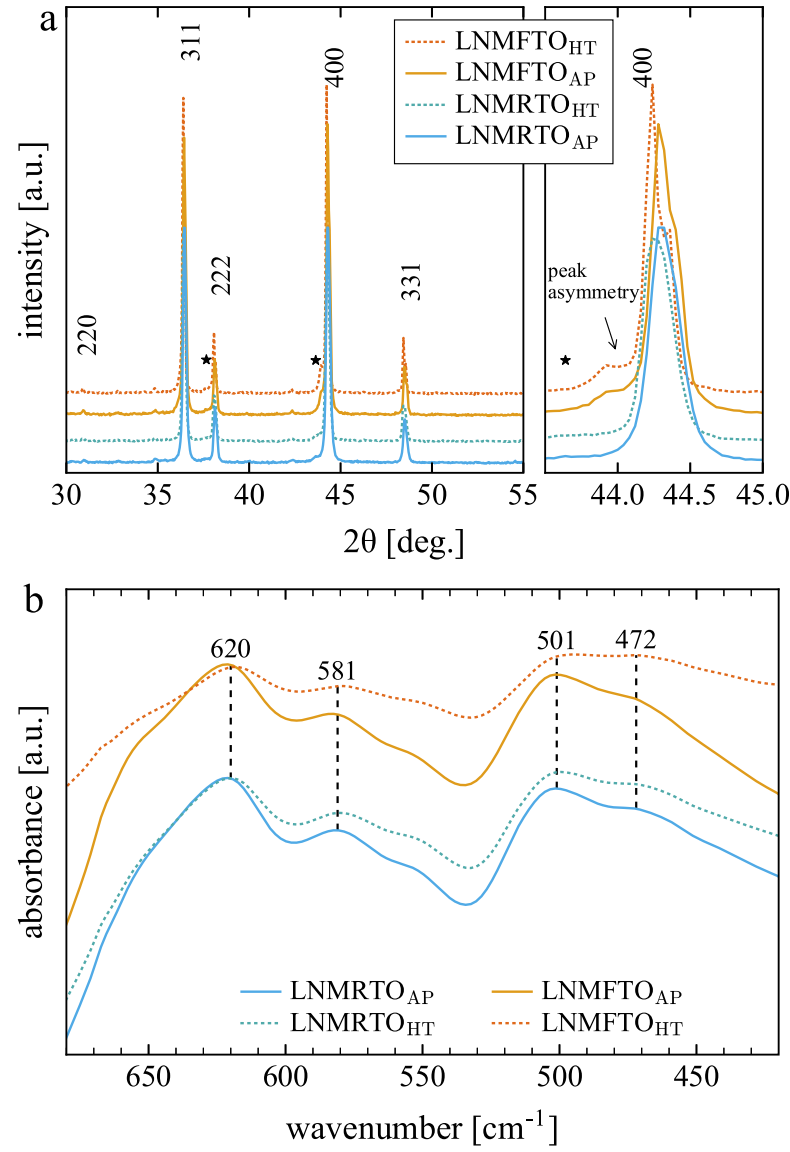

Figure 2. Structural analysis of the LNMFTO and LNMRTO samples. a: XRD patterns (from bottom to top: $\mathrm{LNMRTO}_{\mathrm{AP}}, \mathrm{LNMRTO}_{\mathrm{HT}}, \mathrm{LNMFTO}_{\mathrm{AP}}$, $\mathrm{LNMFTO}_{\mathrm{HT}}$ ), the rock salt impurity phase is marked with an asterisk b: FTIR spectra of the powder samples (in the wavenumber range from 400 to $\left.700 \mathrm{~cm}^{-1}\right)$.

occurs at temperatures above $700^{\circ} \mathrm{C} .{ }^{41}$ The loss of oxygen cannot be fully compensated at high cooling rates. ${ }^{42}$ This process leads to the reduction of $\mathrm{Mn}^{4+}$ to the larger $\mathrm{Mn}^{3+42}$ and thus the expansion of the lattice parameter. ${ }^{28}$ Additionally, a greater formation of the rock-salt impurity phase is observed.

As the diffraction patterns in Figure 2a suggest, the Rietveld refinement results show an occupation of the 8a tetrahedral site with transition metals. The assumption of more transition metal on the $8 \mathrm{a}$ site for the LNMFTO material is confirmed. Based on the results it is assumed that $\mathrm{Fe}^{3+}$ shows a higher tendency to occupy the tetrahedral site.

The choice of the $\mathrm{Fd} \overline{3} \mathrm{~m}$ space group for refinement is supported by FT-IR analysis (Figure 2b). The typical IR-bands of the spinel are

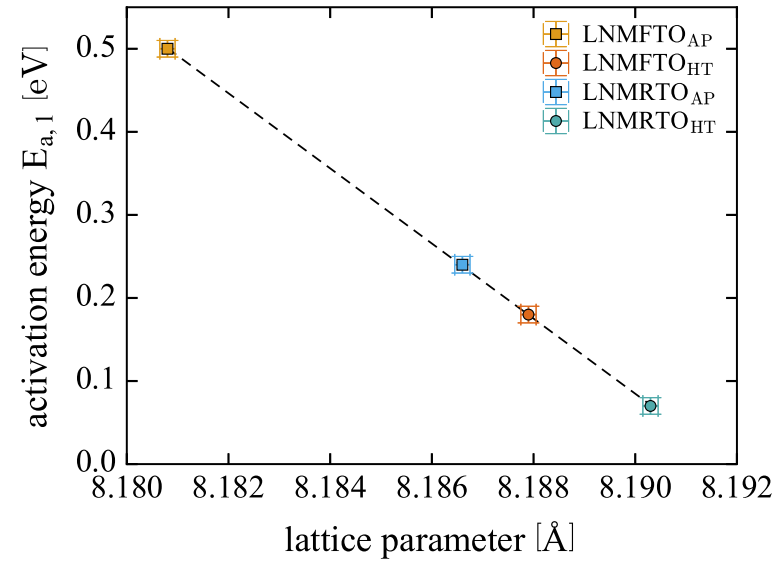

Figure 3. Change of activation energy $\left(\mathrm{E}_{\mathrm{a}, 1}\right)$ for bulk conductivities ( $\left.\sigma_{\mathrm{EIS}, 1}\right)$ with increase of lattice parameter.

observed. However, the bands are more distinct for the AP materials. Several studies report that a low ratio of the 581 band to the 620 band indicates a lower ordering regarding the transition metals nickel and manganese on the octahedral 16d sites. ${ }^{38,41,43}$ Based on this, LNMRTO exhibits a lower ordering than LNMFTO.

The bulk conductivity of the material is measured by means of electrochemical impedance spectroscopy (EIS). The AP samples display two semicircles while the HT samples only show one semicircle (s. Figure S3 and Figure S4). The second semicircle in the low frequency region of the AP samples is possibly due to the lower applied sintering temperature and thus a low density of the pellet (Table I). This can lead to an increased grain boundary resistance. The conductivity of the materials is derived from the impedance data by fitting. For the fit either one parallel RC-element (HT samples) or two parallel RCelements (AP samples) are used. It is assumed that the grain boundary resistance and the respective capacitances for the HT samples are in the same order of magnitude as the bulk resistance and capacitance and therefore no distinction can be made. Thus, two conductivities are derived for AP materials namely $\sigma_{\mathrm{EIS}, 1}$ (bulk) and $\sigma_{\mathrm{EIS}, 2}$ (grain boundary). For the HT materials only $\sigma_{\mathrm{EIS}, 1}$ is derived. Arrhenius plots of the measured conductivities are given in Figure S5. Additionally to the EIS measurement, I-V curves are recorded on individual particles of the material in the SEM. The I-V curves are used to determine the electrical conductivities of the materials $\left(\sigma_{\mathrm{SEM}}\right)$. Further details for the determination of the $\sigma_{\text {SEM }}$ values are given in the Supporting Information.

The conductivities derived from EIS and I-V curves, as well as activation energies $\left(\mathrm{E}_{\mathrm{a}}\right)$ calculated from EIS measurements are listed in Table III. In Figure 3 the activation energies of the different materials are shown in dependence of the lattice parameters (s. Table II). As it was observed previously ${ }^{28,38}$ an increase of the lattice parameter (from 8.1808 to $8.1903 \AA$ ) leads to a decrease of the activation energy

\footnotetext{
Table III. Bulk conductivities and activation energies derived by EIS ( $\left.\sigma_{\text {EIS }}\right)$ and measuring of I-V curves in SEM microscope $\left(\sigma_{\text {SEM }}\right)$ as well as $\mathrm{Mn}^{3+}$ content.
}

\begin{tabular}{|c|c|c|c|c|c|c|}
\hline Sample & $\sigma_{\mathrm{EIS}, 1}\left[\mathrm{~S} \mathrm{~cm}^{-1}\right]^{\mathrm{a}}$ & $\sigma_{\mathrm{EIS}, 2}\left[\mathrm{~S} \mathrm{~cm}^{-1}\right]^{\mathrm{a}}$ & $\mathrm{E}_{\mathrm{a}, 1}[\mathrm{eV}]$ & $\mathrm{E}_{\mathrm{a}, 2}[\mathrm{eV}]$ & $\sigma_{\mathrm{SEM}}\left[\mathrm{S} \mathrm{cm}^{-1}\right]^{\mathrm{b}}$ & $\mathrm{Mn}^{3+}[\%]^{\mathrm{c}}$ \\
\hline LNMFTO $_{A P}$ & $(1.0 \pm 0.3) \cdot 10^{-5}$ & $(6.4 \pm 0.9) \cdot 10^{-8}$ & $0.50 \pm 0.01$ & $0.38 \pm 0.01$ & $(2.2 \pm 1.7) \cdot 10^{-5}$ & 7 \\
\hline LNMFTO $_{\mathrm{HT}}$ & $(1.3 \pm 0.2) \cdot 10^{-5}$ & - & $0.18 \pm 0.01$ & - & $(7.7 \pm 6.5) \cdot 10^{-5}$ & 11 \\
\hline $\mathrm{LNMRTO}_{\mathrm{AP}}$ & $(3.7 \pm 2.0) \cdot 10^{-4}$ & $(1.7 \pm 0.7) \cdot 10^{-6}$ & $0.24 \pm 0.01$ & $0.28 \pm 0.01$ & $(2.5 \pm 0.9) \cdot 10^{-4}$ & 7 \\
\hline LNMRTO $_{\mathrm{HT}}$ & $(8.7 \pm 2.9) \cdot 10^{-5}$ & - & $0.07 \pm 0.01$ & & $(1.5 \pm 1.0) \cdot 10^{-4}$ & 8 \\
\hline
\end{tabular}


(from 0.5 to $0.07 \mathrm{eV}$ ). However in the previous studies this was observed on undoped LNMO spinels, which were annealed at different temperatures. ${ }^{28,38}$ The increase of the lattice parameter and decrease in activation energy was attributed to an increase of the $\mathrm{Mn}^{3+}$ content, which improves the electronic conduction of the spinel due to electron hopping between $\mathrm{Mn}^{3+}$ and $\mathrm{Mn}^{4+}{ }^{28,38}$ Here, within one system of dopants, an increase of $\mathrm{Mn}^{3+}$ is also observed (s. Table II) and thus the decrease of activation energy can be explained correspondingly. The $\mathrm{Mn}^{3+}$ content is calculated from the first discharge curves of the different doped materials (Figure 4b). Since both dopant systems follow the same line of decreased activation energy with lattice parameter, while the $\mathrm{Mn}^{3+}$ content does not increase accordingly, a combined effect of $\mathrm{Mn}^{3+}$ content and the dopant ( $\mathrm{Fe}$ or $\mathrm{Ru}$ ) is assumed to be responsible.

In general, the Fe- and Ti-doped (ca. $1 \cdot 10^{-5} \mathrm{~S} \mathrm{~cm}^{-1}$ ) spinel exhibits one order of magnitude lower conductivities as the Ru- and Tidoped spinel (ca. $1-4 \cdot 10^{-4} \mathrm{~S} \mathrm{~cm}^{-1}$ ). Interestingly the $\mathrm{LNMFTO}_{\mathrm{HT}}$ sample has a slightly higher conductivity as $\mathrm{LNMFTO}_{\mathrm{AP}}$ at room temperature. However, as $\mathrm{LNMFTO}_{\mathrm{AP}}$ displays a higher activation energy $(0.5 \mathrm{eV})$ compared with LNMFTO $_{\mathrm{HT}}(0.18 \mathrm{eV}), \mathrm{LNMFTO}_{\mathrm{AP}}$ exhibits a higher bulk conductivity at increased temperatures (s. Figure S5).

For the Ru-doped material the $\mathrm{LNMRTO}_{\mathrm{AP}}$ spinel exhibits the higher bulk conductivity. While both applied methods yield different absolute values for the conductivity, the general trend is observed regardless of the used method. The observed values for LNMFTO are in the range or slightly higher than values of undoped $\mathrm{LNMO}^{38}$ and for the ruthenium doped material conductivities similar to values of Wang et al. ${ }^{24}$ are measured.
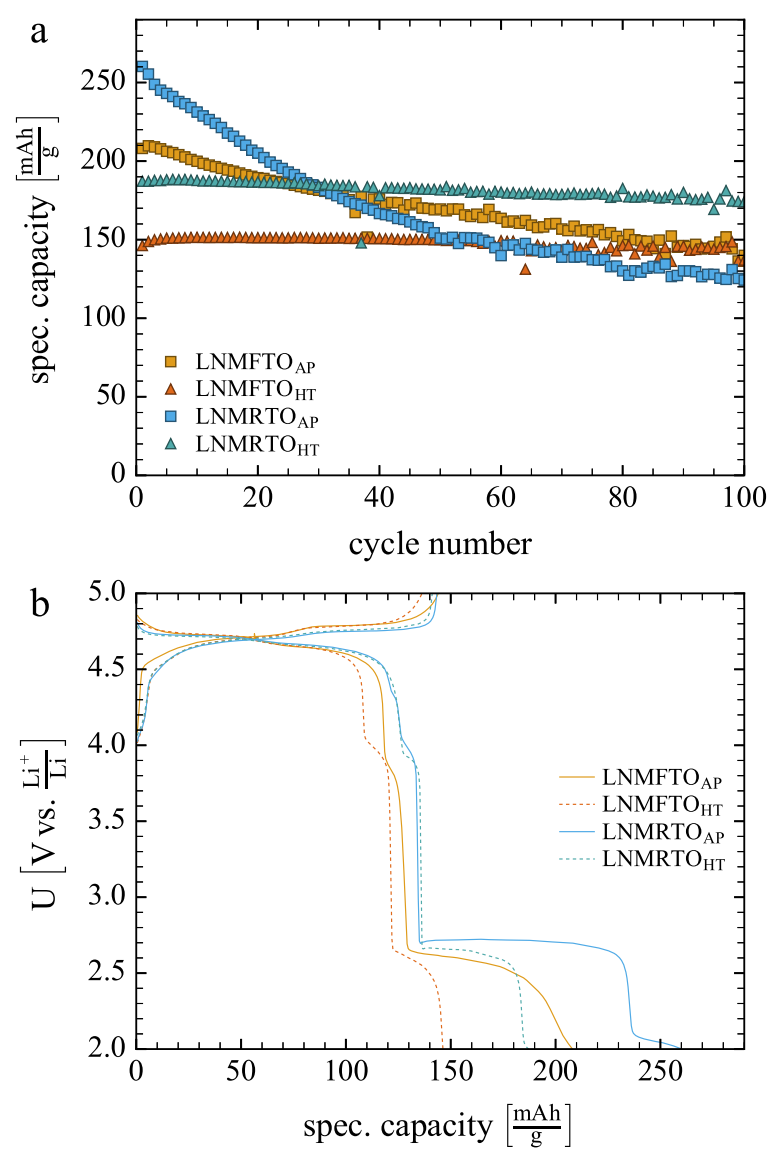

Figure 4. Cycling tests at a rate of $\mathrm{C} / 2$ (based on $1 \mathrm{Li}$ eq.) of the four materials. The specific discharge capacities are given in (a) and the charge and discharge curve of the second cycle in (b). The voltage window was 2.0 to $5.0 \mathrm{~V}$ vs. $\mathrm{Li}^{+} / \mathrm{Li}$. Cycling was performed at a temperature of $23^{\circ} \mathrm{C}$.
Electrochemistry.-The cycling stability of the four materials is tested with galvanostatic cycling at a rate of $\mathrm{C} / 2$ calculated for $1 \mathrm{Li}$ eq. Tests are performed in a voltage window of 2.0-5.0 $\mathrm{V}$ in order to incorporate a second lithium in the spinel. The discharge capacity and the charge and discharge curves are given in Figure 4.

Several differences between the materials are visible. The AP materials exhibit higher initial capacities compared with the HT materials. Both LNMRTO are superior to LNMFTO materials. Especially $\mathrm{LNMRTO}_{\mathrm{AP}}$ with a value of $260 \mathrm{mAh} \mathrm{g}^{-1}$ which is $92 \%$ of the theoretical capacity displays a very good initial capacity. On the other hand, $\mathrm{LNMFTO}_{\mathrm{HT}}$ reaches $150 \mathrm{mAh} \mathrm{g}^{-1}$ which is only slightly more than the theoretical capacity for the cycling of $1 \mathrm{Li}$. No capacity increase is observed and thus no additional energy can be cycled. Apart from the different initial capacities the cycling stability is also heavily influenced by the different temperature treatments. The HT samples exhibit better cycling stability. The capacity retention increases from values of $48 \%\left(\mathrm{LNMRTO}_{\mathrm{AP}}\right)$ and $68 \%\left(\mathrm{LNMFTO}_{\mathrm{AP}}\right)$ to values of over $90 \%$. Considering the whole cycling test, LNMRTO $_{\mathrm{HT}}$ shows the best electrochemical behavior.

In Figure $4 \mathrm{~b}$ the voltage profiles of the materials are given. Above $3.5 \mathrm{~V}$ vs. $\mathrm{Li}^{+} / \mathrm{Li}$ the materials behave similar. The ruthenium doped samples reach discharge capacities of $135 \mathrm{mAh} \mathrm{g}^{-1}$, which are close to the theoretical capacity. LNMFTO only shows capacities of 126 and $120 \mathrm{mAh} \mathrm{g}^{-1}$ for $\mathrm{LNMFTO}_{\mathrm{AP}}$ and $\mathrm{LNMFTO}_{\mathrm{HT}}$, respectively. It is obvious that the Fe- and Ti-doped samples are inferior to the $\mathrm{Ru}$ and Ti-doped samples. Possibly the second spinel phase, revealed by XRD analysis, does not participate in the electrochemical reactions and thus limits the usable capacity. A rough estimate based on the Rietveld refinement yields theoretical capacities of 124 and $119 \mathrm{mAh}$ $\mathrm{g}^{-1}$ for $\mathrm{LNMFTO}_{\mathrm{AP}}$ and $\mathrm{LNMFTO}_{\mathrm{HT}}$, respectively. These values are very close to the experimentally observed ones.

Below $3.5 \mathrm{~V}$ vs. $\mathrm{Li}^{+} / \mathrm{Li}$ more differences are visible. The high initial capacity of $\mathrm{LNMRTO}_{\mathrm{AP}}$ can be attributed to the large plateau at $2.7 \mathrm{~V}$ and a smaller sloping plateau at $2.1 \mathrm{~V} \mathrm{vs} . \mathrm{Li}^{+} / \mathrm{Li}$. For the other samples the $2.7 \mathrm{~V}$ plateau is smaller and not very distinct, or in case of LNMRTO $_{\mathrm{HT}}$ a very small, $2.1 \mathrm{~V}$ plateau is observed. For $\mathrm{LNMFTO}_{\mathrm{AP}}$ no clear distinction between the 2.7 and the $2.1 \mathrm{~V}$ plateau is possible.

In Figure 5 the change in discharge curves during the cycling test can be seen. The capacity loss occurs first in the low voltage region. The length of the $2.7 \mathrm{~V}$ plateau is decreased and the slope is increasing. With increasing cycle number, a loss of the high voltage capacity can be observed. This loss is more severe for the AP samples. It is assumed that the high degree of lithium intercalation and the resulting increase of the c-axis parameter of the tetragonal phase ${ }^{11,12}$ lead to mechanical stress in the material. Parts of the material become electrochemically inactive and thus a simultaneous capacity loss in the low and the high voltage region is observed.

In the following part of this work only the Ru- and Ti-doped material is characterized in more detail, because this material shows superior electrochemical performance, higher conductivities and higher phase purity compared to the LNMFTO material. Especially the differences below $3.5 \mathrm{~V}$ are more distinct for LNMRTO and it is the purpose of this work to evaluate the influence of not only doping but also synthesis and cycling conditions on the cycling stability during cycling between 2.0 and $5.0 \mathrm{~V}$ vs. $\mathrm{Li}^{+} / \mathrm{Li}$.

The influence of the cycling conditions on the stability is analyzed by variation of the C-Rate (Figures $6 \mathrm{a}$ and $6 \mathrm{~b}$ ) and variation of the cutoff criteria during discharging (Figures $6 c, 6 d$ and Figure 7). The initial capacities, especially of $\mathrm{LNMRTO}_{\mathrm{HT}}$, are increased by decreasing the $\mathrm{C}$-rate. The capacity above $3.5 \mathrm{~V}$ vs. $\mathrm{Li}^{+} / \mathrm{Li}$ reaches almost theoretical capacity at a rate of $\mathrm{C} / 2$ (s. Figure 4), this increase can be attributed to a higher usage of the low voltage capacities. Both materials exhibit similar initial capacities at a rate of $\mathrm{C} / 10$. This result indicates that the usable capacity of $\mathrm{LNMRTO}_{\mathrm{HT}}$ is kinetically limited at higher C-rates when the cell is discharged to $2.0 \mathrm{~V} \mathrm{vs.} \mathrm{Li}^{+} / \mathrm{Li}$.

In addition to the increased capacity a change in capacity fade is observed for lower C-rates. In general, the loss of capacity is inversely proportional to the applied C-rate. For $\mathrm{LNMRTO}_{\mathrm{AP}}$ a severe loss of capacity is observed in the first 20 cycles for $\mathrm{C} / 10$ and $\mathrm{C} / 5$. The 

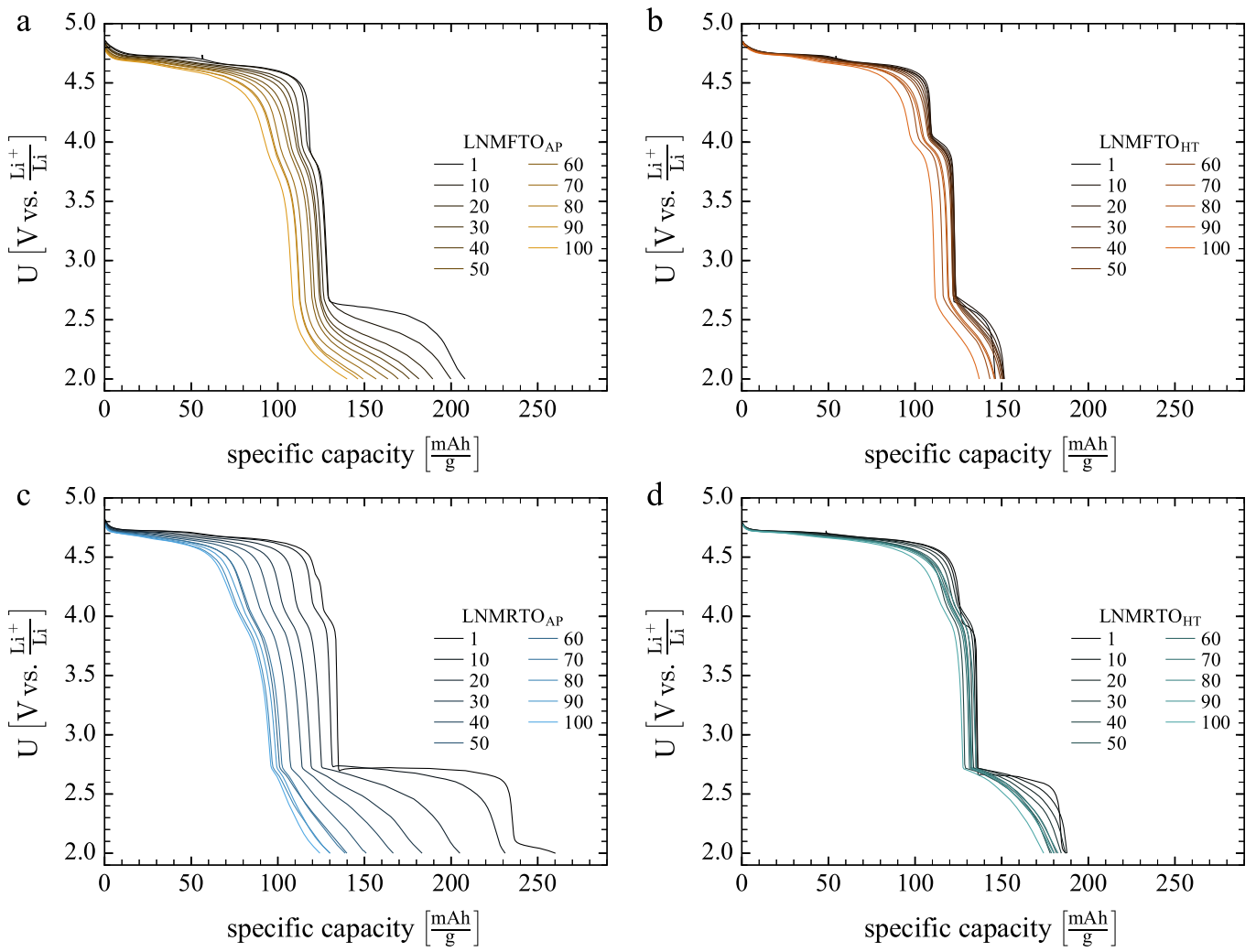

Figure 5. Discharge curves of the different materials at a rate of $\mathrm{C} / 2$. Cycling was performed at a temperature of $23^{\circ} \mathrm{C}$. The voltage window was 2.0 to $5.0 \mathrm{~V}$ vs. $\mathrm{Li}+/ \mathrm{Li}$.
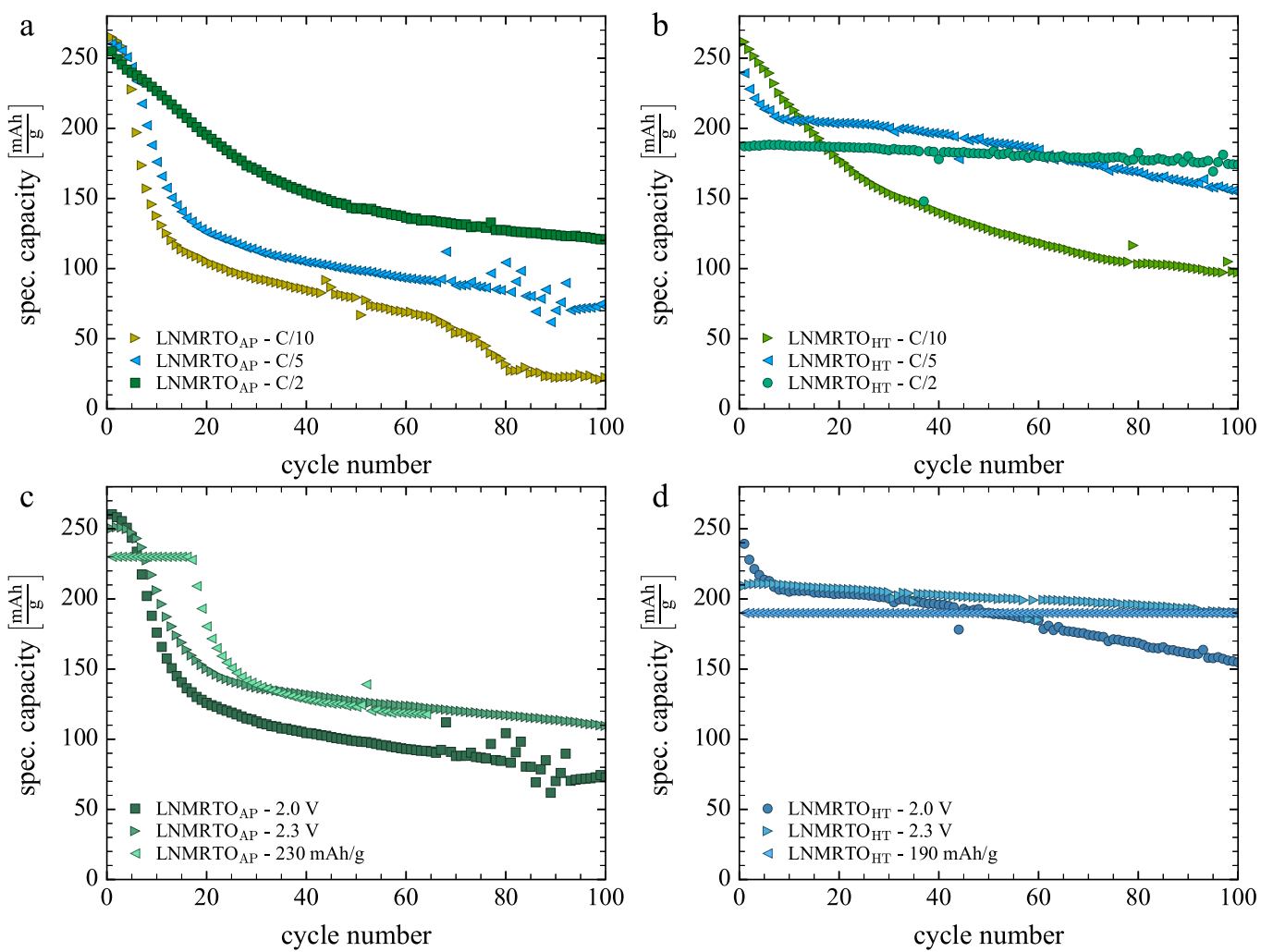

Figure 6. Cycling tests of $\mathrm{LNMRTO}_{\mathrm{AP}}$ (a) and $\mathrm{LNMRTO}_{\mathrm{HT}}$ (b) at rates of $\mathrm{C} / 10, \mathrm{C} / 5$ and $\mathrm{C} / 2$. Different discharge cutoff criteria (2.0 V, $2.3 \mathrm{~V}$ and a capacity limit) were tested at a rate of $\mathrm{C} / 5$ for $\mathrm{LNMRTO}_{\mathrm{AP}}$ (c) and $\mathrm{LNMRTO}_{\mathrm{HT}}(\mathrm{d})$. The voltage window was 2.0 to $5.0 \mathrm{~V}$ vs. $\mathrm{Li}+/ \mathrm{Li}$. Cycling was performed at a temperature of $23^{\circ} \mathrm{C}$. 

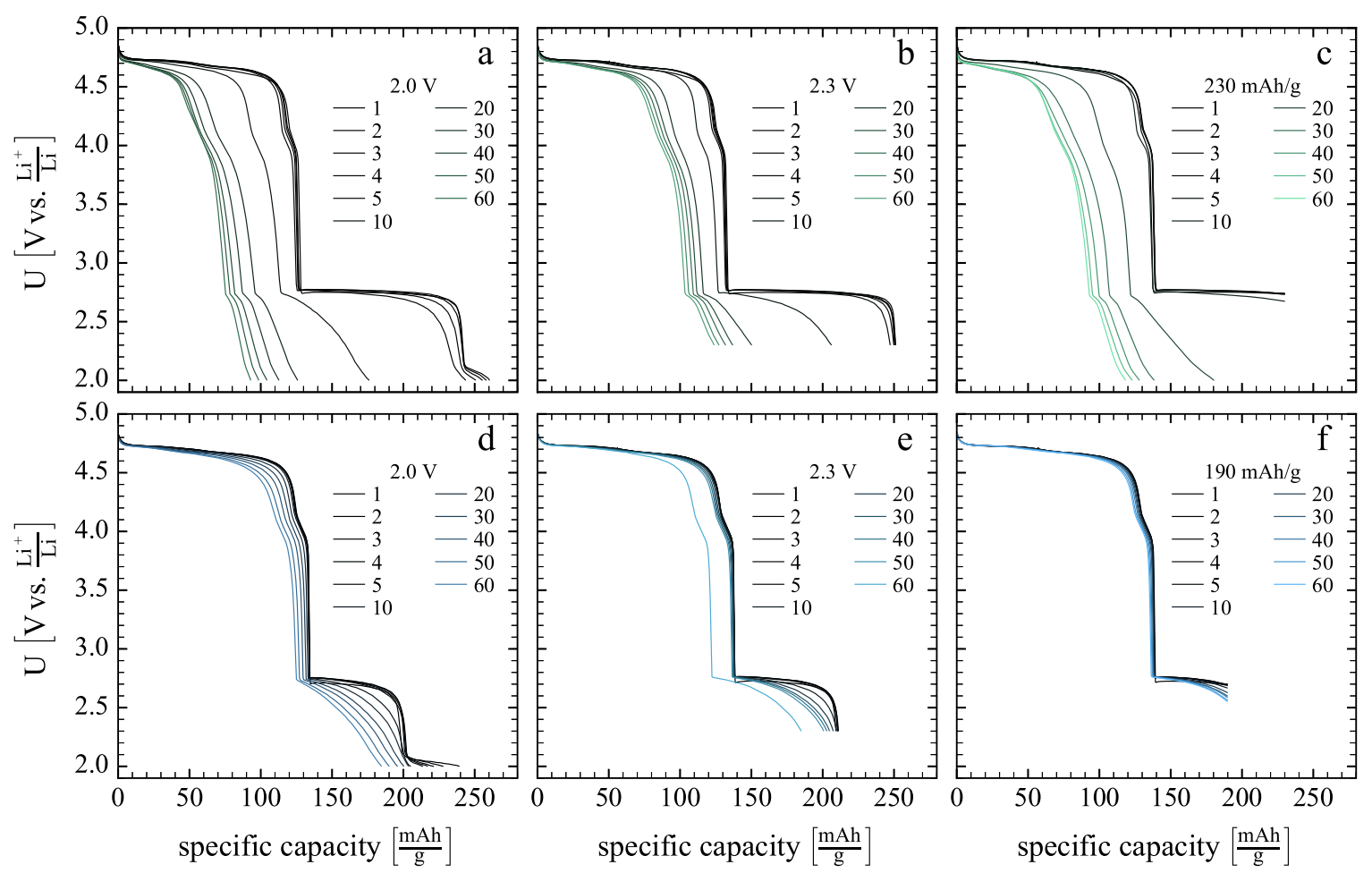

Figure 7. Discharge curves for different cutoff conditions (from left to right: $2.0 \mathrm{~V}, 2.3 \mathrm{~V}$ and a capacity limit) at a rate of $\mathrm{C} / 5$ for $\mathrm{LNMRTO}$ AP (a-c) and LNMRTOHT $_{\text {(d-f). }}$

capacity is reduced to $110-130 \mathrm{mAh} \mathrm{g}^{-1}$ before the loss per cycle reduces significantly. In comparison for $\mathrm{LNMRTO}_{\mathrm{HT}}$ at $\mathrm{C} / 10$ the rate of capacity fade is lower in the beginning. However the capacity retention after 100 cycles is only $37 \%$. At C/5 ca. $35 \mathrm{mAh} \mathrm{g}^{-1}$ are lost in 10 cycles and after that the loss is reduced and a capacity retention of $64 \%$ can be achieved.

Since higher initial capacities, achieved at lower C-rates, lead to an increased capacity fade, the cutoff criteria during discharging are varied. Two additional cutoff limits are tested. The first is a cutoff voltage of $2.3 \mathrm{~V} \mathrm{vs} \mathrm{Li}^{+} / \mathrm{Li}$, which limits the discharging at the point of the voltage drop from the $2.7 \mathrm{~V}$ plateau to the $2.1 \mathrm{~V}$ plateau (Figure 6 and Figure 7). Lee et al. observed a second tetragonal phase with increased c-axis expansion and therefore a higher lattice strain in ex situ XRD studies of discharged samples. ${ }^{6}$ They suggest that this phase transition is associated with the $2.1 \mathrm{~V}$ plateau. The $2.3 \mathrm{~V}$ limit stops discharging before this plateau is reached and therefore the additional stress should be reduced and a better cycling stability should be achieved. As the voltage drop is believed to occur because of the formation of a second tetragonal phase, the phase transition has already started when the voltage is dropping. A second cutoff is limited by a specific capacity and set right before the voltage drop to further improve the cycling stability (Figures $7 \mathrm{c}$ and $7 \mathrm{f}$ ).

The discharge curves in Figure 7 and the discharge capacities in Figure 6 display the different effects, caused by the variation of the discharge cutoff criteria. Setting the cutoff to $2.3 \mathrm{~V} \mathrm{vs}$. $\mathrm{Li}^{+} / \mathrm{Li}$ only has a small effect. The capacity loss during the first cycles is reduced since the $2.1 \mathrm{~V}$ plateau is not cycled. However, after a few cycles the same behavior as for the $2.0 \mathrm{~V}$ limit can be observed. With the standard cutoff limit of $2.0 \mathrm{~V}$ the $2.1 \mathrm{~V}$ plateau is lost after a few cycles and as described before the loss of the low voltage capacity is accompanied by a decrease of the high voltage capacity. Defining a specific capacity for the discharge cutoff leads to a clear improvement of cycling stability for LNMRTO $_{\mathrm{HT}}$. Despite the very good stability in the high voltage region a drop of the $2.7 \mathrm{~V}$ potential can still be observed. This is a sign for material degradation and therefore the capacity will decrease in later cycles.
The variation of the cycling parameters allows for stable cycling during a limited cycle range at the expense of initial capacity. However, the material stability in the long term is not improved. Hence, it is of great interest to further identify the differences between the two materials in the low voltage region and to get information on the occurring phase transitions. To further identify the differences between the materials and the impact on cycling stability, the material cycled at a rate of $\mathrm{C} / 10$ is of high interest, since both materials exhibit similar capacities.

In Figure 8 the potential and the differential capacities of the first two cycles are given. The ratio of the capacity at $2.1 \mathrm{~V}$ to the capacity at $2.7 \mathrm{~V}$ is larger for $\mathrm{LNMRTO}_{\mathrm{HT}}$. Several studies discussed the changes in this ratio. A difference in the transition metal ordering ${ }^{6}$, doping ${ }^{15}$ and morphology in combination with annealing temperature ${ }^{44}$ can lead to a change of this ratio. For the LNMRTO material, a change in ordering is not observed in such an extent, which could account for the change in the ratio. The morphology of the primary particles of LNMRTO$_{\mathrm{AP}}$ is dominated by truncated octahedral compared with the distinct octahedral particles of LNMRTO $_{\mathrm{HT}}$. Based on results of Chemelewski et al., ${ }^{15}$ the combination of truncated octahedral and a lower applied temperature indicate the observed higher ratio of 2.7 to $2.1 \mathrm{~V}$ capacity. The differential capacity plot (Figure $8 \mathrm{~b}$ ) displays the common charging peaks at $4.1 \mathrm{~V}\left(\mathrm{Mn}^{3+} / \mathrm{Mn}^{4+}\right)$ and at $4.7-4.8 \mathrm{~V}$ $\left(\mathrm{Ni}^{2+} / \mathrm{Ni}^{4+}\right)$ and the corresponding discharging peaks.

In the low voltage region the 2.7 and $2.1 \mathrm{~V}$ discharging peaks and the $2.9 \mathrm{~V}$ charging peaks are observed as a result from the $\mathrm{Mn}^{3+} / \mathrm{Mn}^{4+}$ redox couple. This redox reaction is associated with the insertion of lithium into the $16 \mathrm{c}$ octahedral site for spinel materials in the disordered crystal structure. ${ }^{6,12}$ The $2.1 \mathrm{~V}$ peak is linked to an additional charging peak at $3.9 \mathrm{~V}$ vs. $\mathrm{Li}^{+} / \mathrm{Li}$, which is not observed in the first cycle (Figure $8 \mathrm{~b}$ inset). This additional peak has been observed before. ${ }^{6,7,37}$ Based on ex situ XRD measurements Lee et al. assumed that this peak is associated with the phase transition from the tetragonal phase to the cubic spinel phase. ${ }^{6}$ It is obvious that the area of this peak depends on the size of the $2.1 \mathrm{~V}$ plateau. The cycling stability of the different capacity plateaus in the voltage range of 2.0 to $3.5 \mathrm{~V} \mathrm{vs.} \mathrm{Li}^{+} / \mathrm{Li}$ 

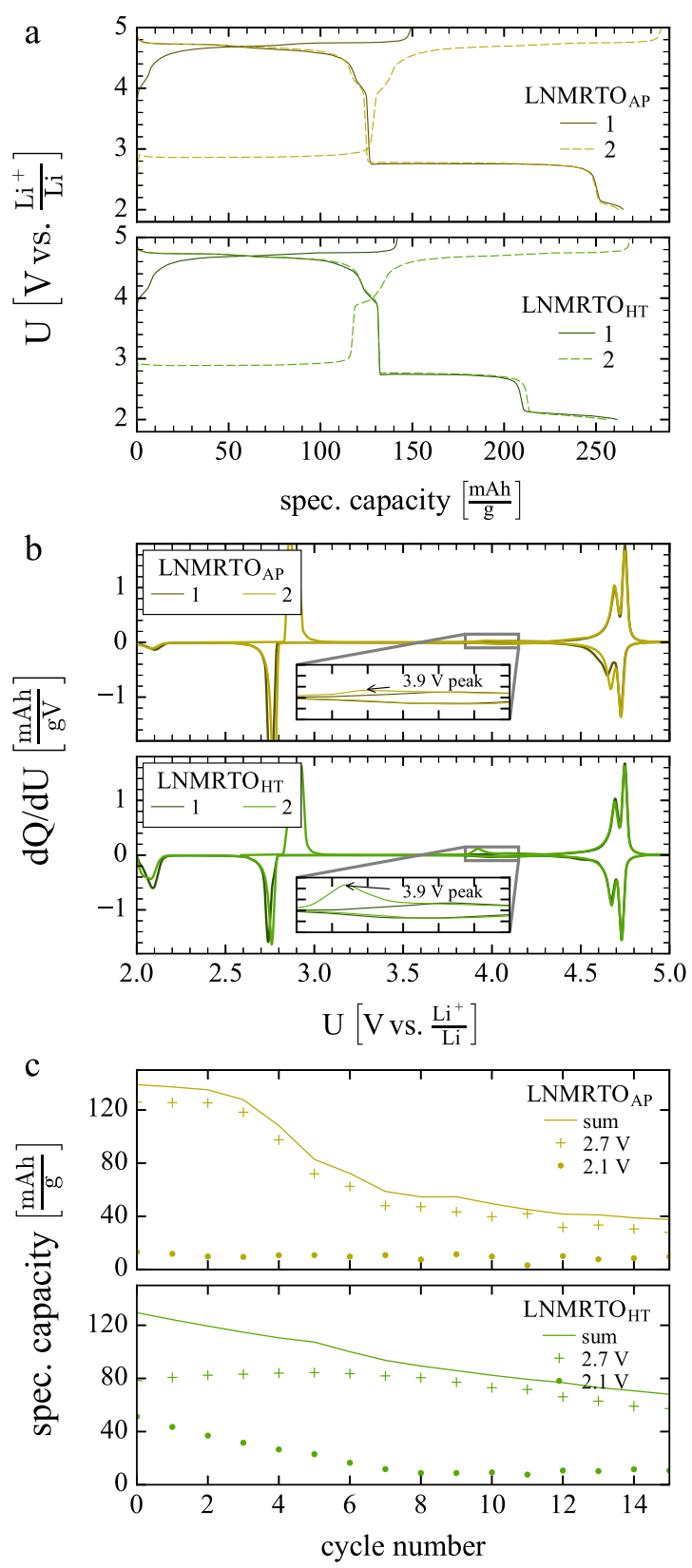

Figure 8. Charge and discharge curves of the first two cycles (a) for

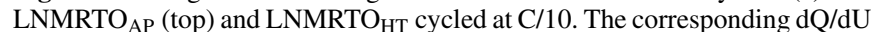
data is given in (b). The cycling stability of the low voltage region $(<3.5 \mathrm{~V}$ vs. $\mathrm{Li}^{+} / \mathrm{Li}$ ) for the first 15 cycles is shown in (c). The capacity is separated in the capacity of the $2.7 \mathrm{~V}$ plateau ( + ) and $2.1 \mathrm{~V}$ plateau (dots) and the sum of both (straight line).

is given in Figure 8c. The boundary between the two plateaus is calculated using the inflexion points between them for each cycle. As discussed before, both materials exhibit a similar sum of capacities in this voltage range but a different ratio between the two plateaus in the first cycles. Interestingly, this ratio determines the extent and the way, the capacity fades. A high ratio from $2.7 \mathrm{~V}$ to $2.1 \mathrm{~V}$ capacity of the LNMRTO $_{\text {AP }}$ sample leads to a fast decrease of the capacity at a voltage of $2.7 \mathrm{~V}$ and thus a severe fade of the overall capacity. For the lower ratio, observed for $\mathrm{LNMRTO}_{\mathrm{HT}}$, the capacity at $2.1 \mathrm{~V}$ is decreased first before the $2.7 \mathrm{~V}$ capacity decreases. The overall capacity loss is lower for $\mathrm{LNMRTO}_{\mathrm{HT}}$.
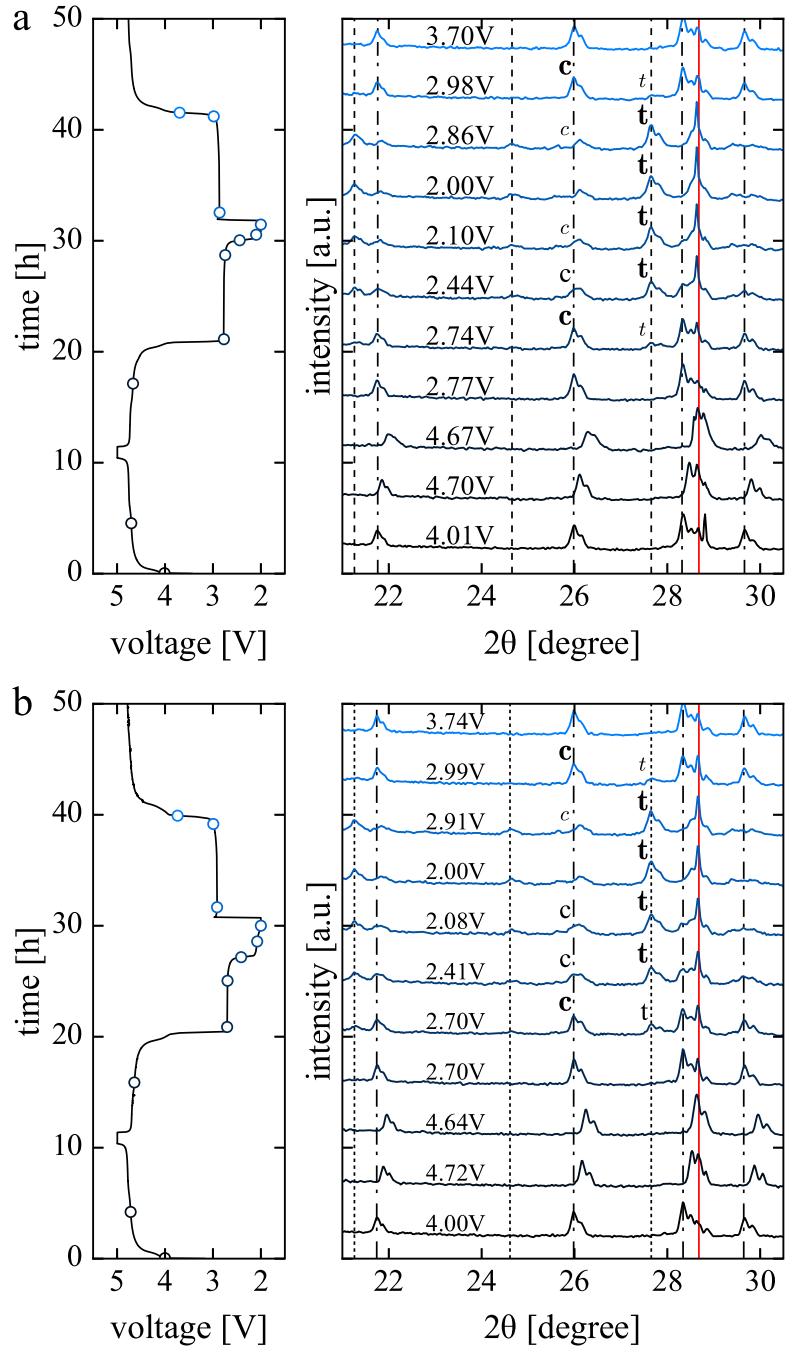

Figure 9. Voltage curve (left) and in situ XRD patterns at selected points (right). The circles in the electrochemical data mark the position of the selected patterns on the right from bottom to top. LNMRTO $_{\mathrm{AP}}$ is given in (a) and LNMRTO $_{\text {HT }}$ in (b). The cell was cycled at a rate of $\mathrm{C} / 10$ and each pattern was recorded for $300 \mathrm{~s}$. In the XRD data cubic peaks are indicated with grey dash-dotted lines, tetragonal peaks are marked with grey dotted lines and the aluminum peak (resulting from pouch and aluminum current collector) is indicated with a red line. Phase reactions during the low voltage region are marked for the $26^{\circ}$ (cubic, c) and $27.6^{\circ}$ (tetragonal, t) peaks. The qualitative phase content is represented by the font (bold text: high phase content, normal text: medium phase content and italic text: low phase content).

In-Situ XRD.-In order to identify the occurring phase changes in-situ XRD measurements are performed. Selected patterns from the first cycle and the second charge half cycle of both materials are given in Figure 9. During charge the well-known shift of the cubic peaks to higher diffraction angles and thus lower lattice parameters is observed. ${ }^{38,45}$ Of more interest is the behavior below $3.5 \mathrm{~V} \mathrm{vs.} \mathrm{Li}^{+} / \mathrm{Li}$. Right after the voltage drops to about $2.7 \mathrm{~V}$, only the cubic phase is observed in both samples. However a voltage plateau is known to be due to a two phase reaction ${ }^{46}$ and in the case of the LNMO spinel system a reaction between the cubic and the tetragonal phase occurs. ${ }^{12}$ Similar to the electrochemical data a difference between the two materials is observed in this voltage region. Right before the voltage drop from ca. 2.7 to $2.1 \mathrm{~V}$ vs. $\mathrm{Li}^{+} / \mathrm{Li}$ a distinct peak of the tetragonal phase can be identified for $\mathrm{LNMRTO}_{\mathrm{HT}}$, while for $\mathrm{LNMRTO}_{\mathrm{AP}}$ only a very weak peak is observed. During the voltage drop both materials exhibit strong tetragonal peaks and only weak cubic peaks. At $2.1 \mathrm{~V} \mathrm{vs.} \mathrm{Li}^{+} / \mathrm{Li}$ the cubic phase has almost vanished 
for $\mathrm{LNMRTO}_{\mathrm{AP}}$ and for $\mathrm{LNMRTO}_{\mathrm{HT}}$ the cubic phase can still be identified. In contrast to other works ${ }^{6,11}$ no second tetragonal phase with lower diffraction angles is observed at 2.0 V. During the following charge half cycle, a jump in the voltage to ca. $2.9 \mathrm{~V}$ vs. $\mathrm{Li}^{+} / \mathrm{Li}$ is observed. At $2.9 \mathrm{~V}$ again a two-phase reaction from tetragonal to the cubic symmetry can be seen. This reaction is finished at ca. $3.7 \mathrm{~V}$ for both materials and the cubic phase has been formed reversely.

The main difference between both materials is the time and thus the state of charge, when the cubic phase is consumed. This occurs during the voltage drop for $\mathrm{LNMRTO}_{\mathrm{AP}}$ and thus earlier than for $\mathrm{LNMRTO}_{\mathrm{HT}}$. As the $2.7 \mathrm{~V}$ plateau is flat and because of a two phase reaction, the sloping plateau at $2.1 \mathrm{~V} \mathrm{vs.} \mathrm{Li}^{+} / \mathrm{Li}$ should be due to a one phase reaction. This is in good agreement with the XRD patterns of $\mathrm{LNMRTO}_{\mathrm{AP}}$. However, for LNMRTO $\mathrm{HT}_{\mathrm{HT}}$ the cubic phase is still present at an observable amount. It is assumed that this is due to a kinetic effect. In Figure S6 the influence of different C-rates on the length of the $2.7 \mathrm{~V}$ plateau for both materials is visible. Liu et al. ${ }^{28}$ found that spinel particles with $\{100\}$ facets show a higher lithium diffusion coefficient than particles with mainly $\{111\}$ facets. As $\mathrm{LNMRTO}_{\mathrm{AP}}$ displays $\{100\}$ facets in contrast to $\mathrm{LNMRTO}_{\mathrm{HT}}$, the assumption of a kinetic effect is supported. This is furthermore in agreement with the observed higher bulk conductivities for $\mathrm{LNMRTO}_{\mathrm{AP}}$.

The particles of $\mathrm{LNMRTO}_{\mathrm{HT}}(\mathrm{d}=0.7 \pm 0.2 \mu \mathrm{m})$ are about 500 $\mathrm{nm}$ larger than $\mathrm{LNMRTO}_{\mathrm{AP}}(\mathrm{d}=0.2 \pm 0.1 \mu \mathrm{m})$ particles. During discharge a core shell like structure is assumed to be formed with the tetragonal phase in the shell and the cubic phase in the core. Eventually the lithium diffusion is not fast enough to reach the core and the shell of all particles consists of the tetragonal phase. The electrochemical reaction is no longer dominated by the two-phase reaction and the voltage drops, although the cubic phase is still present in the center of the particles. With ongoing lithiation not only the shell is further lithiated but also the cubic phase in the core is transformed to the tetragonal phase. The kinetics of the smaller $\mathrm{LNMRTO}_{\mathrm{AP}}$ particles however are sufficient to guarantee a nearly complete transformation from cubic to tetragonal phase before the voltage drops. Based on the XRD results, it is found that the voltage drop is not linked to the formation of an additional phase but to the consumption of the cubic phase. Further detailed in-situ studies will be conducted in order to confirm these findings.

\section{Conclusions}

High capacities can be reached when the LNMO spinel is cycled in a voltage range of $2.0-5.0 \mathrm{~V}$ vs. $\mathrm{Li}^{+} / \mathrm{Li}$. In order to reduce capacity fade different doped materials, synthesis conditions and a variation of cycling parameters are analyzed. It is found that regarding capacities ruthenium doping is superior to iron doping. This is due to a high amount of impurity phase for the iron doped material, which is assumed to be electrochemically inactive. Disregarding the absolute capacities, the differences in cycling stability are similar. Both materials are subjected to an additional heat treatment, which highly improves the cycling stability at the cost of capacity. However, $190 \mathrm{mAh} \mathrm{g}^{-1}$ were reached at a rate of $\mathrm{C} / 2$ with a capacity retention of ca. $92 \%$. The change of cycling condition, especially limiting the discharge capacity, can further improve the capacity retention but does not impede the degradation of the material. It is found that a high ratio of the $2.7 \mathrm{~V}$ to $2.1 \mathrm{~V}$ capacity leads to a more severe capacity fade.

Both ruthenium doped materials exhibit similar structural changes from cubic to tetragonal symmetry in the low voltage region. However, the state of charge, when these changes occur, is different. It is observed, that for $\mathrm{LNMRTO}_{\mathrm{AP}}$ the cubic phase is almost completely consumed after the voltage drops from $2.7 \mathrm{~V}$ to $2.1 \mathrm{~V}$ vs. $\mathrm{Li}^{+} / \mathrm{Li}$. This is consistent with a two-phase reaction building a plateau and a voltage change when one phase is consumed. For $\mathrm{LNMRTO}_{\mathrm{HT}}$ a considerable amount of the cubic phase is still observed. It is concluded, that this is due to a kinetic effect. A core-shell structure is assumed to be formed because of larger primary particles in combination with reduced lithium diffusion. This could lead to a voltage drop despite the ongoing existence of the cubic phase.

\section{Acknowledgments}

The authors thank the Federal Ministry of Education and Research for financial support in the context of the DESIREE project (03SF0477C). Furthermore the authors are grateful for the valuable support of this work by Nicole Bohn, Margarete Offermann, Maximilian Binzler and Daniela Linder (IAM-KWT, SEM images and powder synthesis/analysis). The elemental analysis (Thomas Bergfeldt, IAMAWP) was carried out with the support of the Karlsruhe Nano Micro Facility (KNMF, www.knmf.kit.edu), a Helmholtz research infrastructure at Karlsruhe Institute of Technology (KIT, www.kit.edu).

\section{References}

1. Y. Gao, K. Myrtle, M. Zhang, J. Reimers, and J. R. Dahn, Phys. Rev. B, 54, 670 (1996).

2. Q. Zhong, J. Electrochem. Soc., 144, 205 (1997).

3. M. Bettge, Y. Li, B. Sankaran, N. D. Rago, T. Spila, R. T. Haasch, I. Petrov, and D. P. Abraham, J. Power Sources, 233, 346 (2013).

4. D. Mohanty, S. Kalnaus, R. A. Meisner, K. J. Rhodes, J. Li, E. A. Payzant, D. L. Wood, and C. Daniel, J. Power Sources, 229, 239 (2013)

5. Y. Li, M. Bettge, B. Polzin, Y. Zhu, M. Balasubramanian, and D. P. Abraham, $J$ Electrochem. Soc., 160, A3006 (2013).

6. E.-S. Lee, K.-W. Nam, E. Hu, and A. Manthiram, Chem. Mater, 24, 3610 (2012).

7. S. H. Park, S.-W. Oh, S. H. Kang, I. Belharouak, K. Amine, and Y.-K. Sun, Elec trochim. Acta, 52, 7226 (2007)

8. M. Bettge, Y. Li, K. Gallagher, Y. Zhu, Q. Wu, W. Lu, I. Bloom, and D. P. Abraham, J. Electrochem. Soc., 160, A2046 (2013).

9. R. Gummow, A. Dekock, and M. Thackeray, Solid State Ionics, 69, 59 (1994).

10. J. Vetter, P. Novák, M. R. Wagner, C. Veit, K.-C. Möller, J. O. Besenhard, M. Winter, M. Wohlfahrt-Mehrens, C. Vogler, and A. Hammouche, J. Power Sources, 147, 269 (2005).

11. M. Wagemaker, F. G. B. Ooms, E. M. Kelder, J. Schoonman, and F. M. Mulder, $J$. Am. Chem. Soc., 126, 13526 (2004)

12. K. Ariyoshi, Y. Iwakoshi, N. Nakayama, and T. Ohzuku, J. Electrochem. Soc., 151 A296 (2004).

13. D. W. Shin, C. A. Bridges, A. Huq, M. P. Paranthaman, and A. Manthiram, Chem. Mater, 24, 3720 (2012).

14. G. T. K. Fey, C.-Z. Lu, and T. P. Kumar, J. Power Sources, 115, 332 (2003).

15. E.-S. Lee and A. Manthiram, J. Mater. Chem. A, 1, 3118 (2013).

16. J.-H. Kim, S.-T. Myung, C. S. Yoon, I.-H. Oh, and Y.-K. Sun, J. Electrochem. Soc., 151, A1911 (2004).

17. H.-J. Kim, B.-S. Jin, C.-H. Doh, D.-S. Bae, and H.-S. Kim, Electron. Mater. Lett., 9, 851 (2013).

18. M. Yavuz, N. Kiziltas-Yavuz, A. Bhaskar, M. Scheuermann, S. Indris, F. Fauth, M. Knapp, and H. Ehrenberg, Zeitschrift für Anorg. und Allg. Chemie, 640, 3118 (2014).

19. M. Schroeder, S. Glatthaar, H. Geßwein, V. Winkler, M. Bruns, T. Scherer, V. S. K. Chakravadhanula, and J. R. Binder, J. Mater. Sci., 48, 3404 (2013).

20. J. Liu and A. Manthiram, J. Phys. Chem. C, 113, 15073 (2009).

21. M. V Reddy, S. S. Manoharan, J. John, B. Singh, G. V. S. Rao, and B. V. R. Chowdari, J. Electrochem. Soc., 156, A652 (2009).

22. M.-L.-P. Le, P. Strobel, F. Alloin, and T. Pagnier, Electrochim. Acta, 56, 592 (2010)

23. H. Wang, H. Xia, M. O. Lai, and L. Lu, Electrochem. commun., 11, 1539 (2009)

24. H. Wang, T. A. Tan, P. Yang, M. O. Lai, and L. Lu, J. Phys. Chem. C, 115, 6102 (2011).

25. N. Kiziltas-Yavuz, A. Bhaskar, D. Dixon, M. Yavuz, K. Nikolowski, L. Lu, R.-A. Eichel, and H. Ehrenberg, J. Power Sources, 267, 533 (2014).

26. K. R. Chemelewski, D. W. Shin, W. Li, and A. Manthiram, J. Mater. Chem. A, 1, 3347 (2013)

27. H. B. Lin, Y. M. Zhang, H. B. Rong, S. W. Mai, J. N. Hu, Y. H. Liao, L. D. Xing, M. Q. Xu, X. P. Li, and W. S. Li, J. Mater. Chem. A, 11987 (2014).

28. H. Liu, J. Wang, X. Zhang, D. Zhou, X. Qi, B. Qiu, J. Fang, R. Kloepsch, G. Schumacher, Z. Liu, and J. Li, ACS Appl. Mater. Interfaces, 8, 4661 (2016)

29. J. Cabana, H. Zheng, A. K. Shukla, C. Kim, V. S. Battaglia, and M. Kunduraci, J Electrochem. Soc., 158, A997 (2011).

30. J. Cabana, M. Casas-Cabanas, F. O. Omenya, N. A. Chernova, D. Zeng, M. S. Whittingham, and C. P. Grey, Chem. Mater, 24, 2952 (2012).

31. S. Brunauer, P. H. Emmett, and E. Teller, J. Am. Chem. Soc., 60, 309 (1938).

32. M. Noyong, K. Blech, A. Rosenberger, V. Klocke, and U. Simon, Meas. Sci. Technol., 18, N84 (2007)

33. M. Hirayama, N. Sonoyama, M. Ito, M. Minoura, D. Mori, A. Yamada, K. Tamura, J. Mizuki, and R. Kanno, J. Electrochem. Soc., 154, A1065 (2007).

34. M. Hirayama, H. Ido, K. Kim, W. Cho, K. Tamura, J. Mizuki, and R. Kanno, J. Am. Chem. Soc., 132, 15268 (2010).

35. T. Ohzuku, K. Ariyoshi, S. Takeda, and Y. Sakai, Electrochim. Acta, 46, 2327 (2001)

36. J. C. Arrebola, A. Caballero, M. Cruz, L. Hernán, J. Morales, and E. R. Castellón, Adv. Funct. Mater., 16, 1904 (2006). 
37. A. Höweling, D. Stenzel, H. Gesswein, M. Kaus, S. Indris, T. Bergfeldt, and J. R. Binder, J. Power Sources, 315, 269 (2016).

38. M. Kunduraci and G. G. Amatucci, J. Electrochem. Soc., 153, A1345 (2006).

39. A. Höweling, S. Glatthaar, D. Nötzel, and J. R. Binder, J. Power Sources, 274, 1267 (2015).

40. R. D. Shannon, Acta Crystallogr., A32, 751 (1976).

41. Y.-C. Jin, C.-Y. Lin, and J.-G. Duh, Electrochim. Acta, 69, 45 (2012).
42. F. M. Vitucci, A. Paolone, O. Palumbo, G. Greco, L. Lombardo, M. Köntje, A. Latini, S. Panero, and S. Brutti, J. Am. Ceram. Soc., 99, 1815 (2016).

43. M. Kunduraci and G. G. Amatucci, Electrochim. Acta, 53, 4193 (2008).

44. K. R. Chemelewski, E. S. Lee, W. Li, and A. Manthiram, Chem. Mater, 25, 2890 (2013).

45. L. Wang, H. Li, X. Huang, and E. Baudrin, Solid State Ionics, 193, 32 (2011)

46. C. M. Julien and A. Mauger, Ionics (Kiel)., 19, 951 (2013). 